\title{
BMJ Open Comparative analysis of reported physical activity from leisure centres' members versus the general population in Spain
}

\author{
Jorge López Fernández (D) , , ${ }^{1,2}$ Alejandro López-Valenciano, ${ }^{3}$ Xián Mayo, ${ }^{3}$ \\ Elizabeth Horton, ${ }^{1}$ Ivan Clavel, ${ }^{4}$ Gary Liguori, ${ }^{5}$ Alfonso Jiménez ${ }^{2,3,6}$
}

To cite: López Fernández J, López-Valenciano A, Mayo X, et al. Comparative analysis of reported physical activity from leisure centres members versus the general population in Spain. BMJ Open 2021;11:e043963. doi:10.1136/ bmjopen-2020-043963

- Prepublication history for this paper is available online. To view these files, please visit the journal online (http://dx.doi. org/10.1136/bmjopen-2020043963).

Received 21 August 2020 Accepted 04 June 2021

Check for updates

(c) Author(s) (or their employer(s)) 2021. Re-use permitted under CC BY-NC. No commercial re-use. See rights and permissions. Published by BMJ.

For numbered affiliations see end of article.

Correspondence to Prof. Alfonso Jiménez; alfonso.jimenez@urjc.es

\section{ABSTRACT}

Objectives (1) To describe the physical activity (PA) levels of the members of a Spanish leisure centre operator according to age and gender; (2) to describe the differences in the three PA levels between the members of a Spanish leisure centre operator and the general Spanish population considering the PA Eurobarometer data according to their gender and age and (3) to explore the intensity origin of the PA either in Spanish members of leisure centres or the Spanish population considering their gender.

Design Descriptive epidemiology study.

Participants Data from 16 Spanish leisure centres ( $n=3627)$ and from the 2017 Eurobarometer 472 for Spain $(n=1002)$ were used for this research.

Primary and secondary outcomes measures The PA levels were analysed with the International Physical Activity Questionnaire short version, and respondents were grouped into physical inactivity (PIA), moderate-PA and high-PA. Moreover, gender (men or women) and age (18-29 years; 30-44 years; 45-59 years; $60-69$ years; $\geq 70$ years) were considered. Total metabolic equivalent (MET)-min/week, as well as total MET-min/week for walking intensity, moderate intensity and vigorous intensity were recorded.

Results Leisure centres showed a lower prevalence of PIA and a higher prevalence of high-PA than the general population $(p<0.05)$. Women displayed a higher prevalence of PIA and lower prevalence of high-PA than men $(p<0.05)$ The prevalence of PIA increases with age while the prevalence of high-PA decreases.

Conclusion Leisure centres engage most of their members in regular PA, including women and older adults, and these members also perform a higher number of MET in vigorous $\mathrm{PA}$, than the general population.

\section{INTRODUCTION}

Physical inactivity (PIA) is defined as the default of the weekly Global Recommendations on physical activity (PA). ${ }^{1}$ It is different to sedentary behaviour which represents those behaviours performed in sitting or lying position with a low level of energy expenditure $(\leq 1.5$ metabolic equivalents (METs) $) .^{2}$

\section{Strengths and limitations of this study}

- This is the first study that describes the prevalence of different levels of physical activity in members of leisure centres according to their age and gender and analyses how this prevalence differs from the general population.

- It also analyses for the first time the intensity origin of the weekly physical activity performed either by the members of leisure centres and the general population according to age and gender.

- The database representing leisure centres contains 3627 responses from 16 leisure centres that were spread in seven Spanish regions.

- The use of a self-reported instrument to measure the physical activity levels might result in an underestimation of the prevalence of the low-physical activity.

The Global Recommendations of PA differ across different age groups (ie, children and adults). Thus, according to the 2020 guidelines, PIA in adults means failing to accumulate $150 \mathrm{~min}$ of moderate-to-vigorous aerobic PA throughout the week $(<600$ MET $\min ){ }^{3}$ This situation is one of the main risk factors for developing of non-communicable diseases and premature death in adults, so it has become a global public health issue. ${ }^{45}$ In Spain, like in other European countries, this issue is not an exception, as the lack of sufficient PA or PIA accounted for 9.3\% of coronary heart disease, $10.3 \%$ of type 2 diabetes, $13.8 \%$ of breast cancer, $14.9 \%$ of colon cancer and $13.4 \%$ of all-cause mortality during 2012. At the same time, life expectancy would increase by 0.78 years if PIA was eliminated. ${ }^{4}$ Moreover, healthcare expenditure attributed by PIA in Spain has been quantified in Int $\$ 2.024$ billion of direct cost, Int $\$ 1.425$ billion costs for the public sector and Int $\$ 461.6$ million costs for households. ${ }^{6}$ 
Thus, reducing the impact of PIA in people's lives, and in public healthcare systems, will bring considerable public health benefits, but remains one of the current challenges for policymakers. ${ }^{78}$

The Global Action Plans in 2013 and 2018 challenges the countries to increase their prevalence of PA by at least $10 \%$ of 2010 baseline data by 2025 and $15 \%$ of 2016 baseline data by $2030 .{ }^{89}$ However, the levels of PA has diminished in Europe within the last 15 years, ${ }^{10} 11$ the same as Spain, where the levels of PA has decreased significantly between 2013 and 2017 in men and women, thereby nullifying the objectives set by the Global Action Plans. ${ }^{8-10}$

The socioecological approach as well as the Global Action Plan suggest that to effectively address PIA, it is required to promote different domains of $\mathrm{PA}$, that is, occupational, travel, home or leisure-time. ${ }^{812}$ Within these domains, leisure-time PA (LTPA) has resulted effective to reduce the cardiovascular risk in the general population $^{13}$ and to improve other health parameters in older adults (ie, body composition, muscle strength or sarcopenia). ${ }^{14}$ Moreover, LTPA reduces the risk of premature death regardless of pre-existing health conditions. ${ }^{15}$ Since recreational facilities such as leisure centres are one of the main LTPA providers for adults, ${ }^{16}$ it might be a good strategy to promote these places to address PIA, ${ }^{17} 18$ and combine this approach with further strategies to promote PA in other domains. ${ }^{12}$ This view aligns with the authors of the latest Global Action Plan as they encourage policymakers to strengthen and enhance the fitness sector together with other sectors (Action 1.4 and Action 3.3) and combine them with other domains of PA. ${ }^{8}$

Focusing on leisure centres as a key source to promote PA is advisable, as they are specifically designed to engage people in regular LTPA, ${ }^{17} 18$ and enjoyed daily by thousands of people, who start, restart or continue with a PA habit. ${ }^{19} 20$ In Spain, for instance, around 5.3 million people ( $\approx 11.4 \%$ of the adult population) are enrolled in a leisure centre. In addition, these centres are designed to address many of the contextual factors that affect people's PA plans (eg, safe environments; social relationship with other users, wide schedule, wide exercise opportunities (individual or collective) and so on), what makes them be a sweet spot for large-scale public PA engagement. ${ }^{20-22}$

Despite these factors, the capability of these centres to promote $\mathrm{PA}$ is unknown as it is the percentage of members who can be considered active. Thus, care must be taken when suggesting these centres for promoting PA. The common sense and the anecdotal evidence might suggest that most of the leisure centre members are adequately active when analysing self-reported $\mathrm{PA},{ }^{23}{ }^{24}$ and they are more active than non-members counterparts. ${ }^{24}$ Nevertheless, the lack of normative values and comparisons with the general population according to the gender and ages do not allow to conclude these facts.

On the other hand, PIA is age-related, with older adults exercising for significantly less time and at lower intensities than younger individuals. ${ }^{25} 26$ It is also gender-related as a higher proportion of women do not engage in sufficient
PA and active women accumulate less weekly MET and perform less time of vigorous exercise than men. ${ }^{10} 1127$ Leisure centres seem to reduce this gap because around half of the members of these centres are women. ${ }^{2021}$ Also, they have been proved to be useful in increasing the PA levels and intensity of older adults. ${ }^{28}$ However, the prevalence pattern of PA among women and elderly members of leisure centres is still unknown. Thus, the objectives of this study were (1) to describe the PA levels of the members of a Spanish leisure centre operator according to gender and age; (2) to describe the differences in the three PA levels between the members of a Spanish leisure centre operator and the general Spanish population considering the PA Eurobarometer data according to their gender and age; (3) to explore the intensity origin of the PA either in Spanish members of leisure centres or the Spanish population considering their gender.

It is expected that this work provides normative values about the prevalence of PA in leisure centres according to the age and gender what might help to understand the effectiveness of these places for promoting PA. Moreover, since the WHO is encouraging the policymakers to strengthen the leisure centres in order to improve PA levels of modern societies, ${ }^{8}$ the findings from this work might help to set the role of leisure centres to address PIA in different populations.

\section{MATERIALS AND METHODS}

\section{Study design and data sources}

This is a descriptive epidemiology study. The data used in this study come from two different databases. The first one is the 2018 GO fit Observatory raw data, which was provided by a Spanish leisure centres operator (GO fitIngesport Health \& Spa Consulting SA) that periodically survey its customers about their current PA and service satisfaction. This survey was conducted via online between January and June of 2018. The sample inquired comes from 16 fitness and leisure centres $(\mathrm{n}=3627)$, which are spread in 7 of the 17 Spanish Regions (Andalucía, Cantabria, Castilla y León, Castilla-La Mancha, Comunidad de Madrid, Gran Canarias and Principado de Asturias). The survey used a stratified random design based on the number of members per centre, their gender and their age. All leisure centres were operated by a private organisation and were equipped by an indoor swimming pool, several spaces for collective classes and a fitness room. All centres offered different sort of exercise services including individualised exercise programmes and collective classes (eg, endurance, dancing, jumping, well-being and so on) and nutritional services. The second database comes from the 2017 Special Eurobarometer 472, ${ }^{29}$ a public opinion surveys that the European Commission simultaneously conducts on all the European Union state members to understand the levels of PA and sports participation of each country's population. In this case, data were obtained from the adult Spain population $(n=1002)$ a few months before GO fit-Ingesport conducted their 
2018 Observatory survey. The Eurobarometer surveys are conducted under a multistage sampling, random design. In order to cover the whole territory of the country, the number of sampling points is drawn with probability proportional to both population size and population density. To this purpose, the age, gender, region and the size of the locality are introduced in the iteration procedures. $^{29}$

\section{Measurements}

Both data sources used the short form of the International Physical Activity Questionnaire (IPAQ), which is used to inquire about the levels of PA. ${ }^{30}$ This instrument measures the intensity, frequency and duration of PA performed within the previous 7 days by examining the number of days performing vigorous, moderate and walking PA and the total minutes during those days. ${ }^{30}$ The 2018 GO fit Observatory used an online version of the short form of the IPAQ with the classical open solution as responses were not truncated. On the contrary, the Special Eurobarometer 472 survey used a modified version of the IPAQ with responses truncated to five different fixed possibilities, instead of the classical open solution, to indicate the minutes performed in each activity. ${ }^{29}{ }^{30}$ In order to reduce the bias due to the approach differences between databases both sources, the responses from the GO fit Observatory were truncated according to the methodology used in the Special Eurobarometer 472. Thus, for the case of $\mathrm{PA}$, in both cases a response of ' $30 \mathrm{~min}$ or less' was assumed to mean $15 \mathrm{~min}$, a response of ' 31 to 60 min' was assumed to mean $45 \mathrm{~min}$, a response of ' 61 to $90 \mathrm{~min}$ ' was assumed to mean $75 \mathrm{~min}$, a response of ' 91 to $120 \mathrm{~min}$ ' was assumed to mean $105 \mathrm{~min}$ and a response of 'more than 120 min' was assumed to mean 120 min. $^{31}$

The data processing and analysis were completed using a modified ad hoc spreadsheet available online ${ }^{32}$ according to the instruction for data processing and analysis of the IPAQ short form ${ }^{30}$ and the methodology used in recent studies. ${ }^{10}{ }^{11}$ Only individuals with at least one valid intensity and duration of a particular intensity (ie, both variables with a different answer than 'don't know') were analysed. In this regard, 'Moderate-PA' was considered when reporting (a) at least 3 days of vigorous intensity activity of at least $20 \mathrm{~min}$ per day; (b) at least 5 days of moderate intensity activities and/or walking for at least 30 min per day or (c) at least 5 days combining the intensities mentioned above achieving at least 600 MET-min/ week. 'High-PA' was considered when reporting (d) three or more days of vigorous-intensity activity of at least $20 \mathrm{~min}$ per day; or (e) five or more days of moderate-intensity activity and/or walking of at least $30 \mathrm{~min}$ per day MET$\mathrm{min}$ /week. 'Low-PA' (inactive or PIA) was considered if not meeting any of these thresholds. ${ }^{30}$ Moreover, moderate-PA and high-PA were considered as active. The METs of the respondents were calculated accordingly to the existing guidelines so that walking-intensity, moderateintensity and vigorous-intensity accounted for 3.3, 4.0 and 8.0 METs, respectively. ${ }^{30}$ Thus, walking, moderate and vigorous MET-min/week were calculated by multiplying the selected MET value by the minutes and days of each intensity. The total PA MET-min/week was obtained by summing up the walking, moderate and vigorous MET$\mathrm{min} /$ week score. On the other hand, in order to explore the origin of the MET-min/week for the three groups of PA analysed (low-PA, moderate-PA and high-PA), the average MET-min/week for walking, moderate and vigorous PA and total average MET-min/week in each group were calculated. Using these values, the proportion (\%) of MET-min/week coming from walking, moderate and vigorous activities was also estimated.

\section{Statistical analysis}

For the analysis of PA prevalence levels (low-PA, moderate-PA and high-PA), data were displayed as a proportion (\%) with $95 \%$ CI. In this regard, analysis between the leisure centres and the Eurobarometer was analysed with a $\chi^{2}$ test for the overall sample and separately by gender and age groups (18-29 years, 30-44 years, $45-59$ years, $60-69$ years and $\geq 70$ years). Z-score for two population proportions was used for this purpose. A $\chi^{2}$ test for the overall sample and separately by the gender and age was also used to compare the origin of the MET-min/week for the three PA groups (low-PA, moderate-PA and high-PA) between members from the leisure centres and people from the Eurobarometer. Once again, Z-score for two population proportions was used for this purpose. These tests were conducted using Microsoft 365 Excel V.2003 (Build 12624.20320; Microsoft Corporation; Redmond, Washington, USA). On the other hand, the differences in total MET-min/week between leisure centres and Eurobarometer, also considering gender, were analysed by a two-way Analysis of Variance (ANOVA). To this purpose, linearity, skewness and asymmetry were considered. These analyses were conducted using the Statistical Package for Social Sciences (V.22.0, SPSS). The level of significance was established at 0.05 .

\section{Patient and public involvement}

The authors confirm that patient and public was not involved in the research.

\section{RESULTS}

Demographic data from the participants in both leisure centres' survey and Eurobarometer survey are displayed in table 1 . In both databases, slightly more women were recruited than men. Moreover, members of leisure centres were younger than those representing the Spanish population $(-8.68$ years).

As can be identified in table 2, significant differences were found in the three levels of PA between leisure centres and the general Spanish population. In this regard, the percentage of low-PA population was significantly higher in the general Spanish population either for the whole sample or for women and men separately $(\mathrm{p}<0.001)$. The prevalence of moderate-PA was also 
Table 1 Participants' demographic characteristics

\begin{tabular}{llllll}
\hline Database & \# Women & \% Women & \# Men & \% Men & Age* \\
\hline $\begin{array}{l}\text { GO fit-Ingesport operated leisure centre } \\
\text { (GO fit Observatory) }\end{array}$ & 1898 & 52.3 & 1729 & 47.7 & $42.67 \pm 12.05$ \\
$\begin{array}{l}\text { Spanish general population (Special } \\
\begin{array}{l}\text { Eurobarometer 472) } \\
\text { S }\end{array}\end{array}$ & 555 & 55.4 & 447 & 44.6 & $51.35 \pm 18.20$ \\
\hline
\end{tabular}

${ }^{*}$ Age: expressed as mean $\pm S D$

higher in the general Spanish population either for the whole sample, and women and men separately $(p<0.001)$. On the contrary, the GO fit-Ingesport operated leisure centres showed a higher prevalence of high-PA for the whole sample and for women and men separately. Considering gender, women showed a higher low-PA and a lower high-PA prevalence in comparison with men in both samples $(p<0.001-0.015$, respectively). Considering the age of the samples, similar findings were reported as to the total population in which the low-PA population were descriptively increasing with the age brackets and high-PA levels being reduced with every new age bracket.

Table 3 shows the origin of the MET-min/week for the three PA groups (low-PA, moderate-PA and high-PA). The low-PA population and population with moderate-PA levels from GO fit-Ingesport operated leisure centres showed a higher proportion of METs coming from vigorous-intensity and a lower proportion of METs coming from walking than the Spanish population, despite having similar \% METs of moderate intensity. This was confirmed for the whole sample and considering the gender subssamples, except for women in the moderate-PA levels, in which GO fit-Ingesport members also had higher levels of moderate intensity METs than the Spanish population. In high-PA population, there were no differences in the \%METs walking between sample. However, GO fit-Ingesport members reported higher \%METs of vigorous activity and lower \% MET of moderate activity in comparison with the general Spanish population.

Considering gender, there were differences between women and men for all levels and intensities except for the \%METs at moderate-intensity in the GO fit-Ingesport sample and for the low-PA group of the Spanish population regarding \% MET at moderate-intensity $(\mathrm{p}>0.05)$. In this regard, in both samples and in the three levels of intensity, women had a higher percentage of METs coming from walking and a lower percentage of METs coming from vigorous intensity $(\mathrm{p}<0.005)$.

Finally, the total MET-min/week achieved by both samples are displayed in figure 1. Despite no interaction effect between gender and sample was found, the total MET-min/week of GO fit-Ingesport centre members were significantly higher than the general Spanish population (3051.59 METs vs 1784.52 METs; $p<0.001$ ). The same was reported for both women (2732.16 METs vs 1461.07 METs; $\mathrm{p}<0.001)$ and men (3402.26 METs vs 2186.12 METs; $\mathrm{p}<0.001)$. On the other hand, women showed a lower total MET min/week in both the sample from leisure centres and the Spanish population $(\mathrm{p}<0.001)$.

\section{DISCUSSION}

The main findings of this study are that: (a) around $80 \%$ of the members of a Spanish leisure centre operator selfreport to be active; (b) the prevalence of low-PA and moderate-PA in leisure centre members is lower than in the Spanish population, yet the leisure centre members show higher levels of high-PA regardless the age and gender; (c) the prevalence of low-PA is higher in women in both leisure centres and the general population compared with men; (d) members of leisure centres show less low-PA for all age brackets than the general population and (e) the intensity of PA differs according to the total level of individual PA.

The high prevalence of PA in Spanish leisure centres $(84.5 \%)$ is in line with the prevalence reported in leisure centres from the USA $(\sim 88 \%){ }^{23}{ }^{24}$ Gjestvang et al, ${ }^{33}$ using accelerometers found that new members of leisure centres accounted for a lower prevalence of PIA after 12 months than the prevalence of PIA reported by the Norway population in other studies. ${ }^{3435}$ However, no one has specifically and directly described the difference in prevalence of PIA among members of leisure centres to that of the general population, particularly with respect to gender and age. Therefore, our finding that leisure centres' members to have a lower prevalence of PIA than the general population regardless of gender and age group is novel.

Regarding gender, women showed higher PIA prevalence than men, in agreement with previous studies. ${ }^{10} 2736$ Women also perform less vigorous-PA, which may prevent women from gaining the full benefits of PA. ${ }^{37}$ The positive finding is that women from leisure centres reported much higher high-PA ( $40.0 \%$ vs $13.0 \%)$, lower levels of PIA (18.6\% vs $37.3 \%$ ) and higher engagement in vigorous-PA than the general population. Therefore, leisure centres seem to be useful to engage women in regular PA and vigorous PA beyond what is typically seen in the general population. Moreover, women represented $52.3 \%$ of the sample from leisure centres, showing that leisure centres might be useful places to support women in decreasing PIA and increasing PA. ${ }^{20}$ The gender differences in leisure centres, that is, women more engaged in moderate-PA and men in high-PA, may be due to the way 


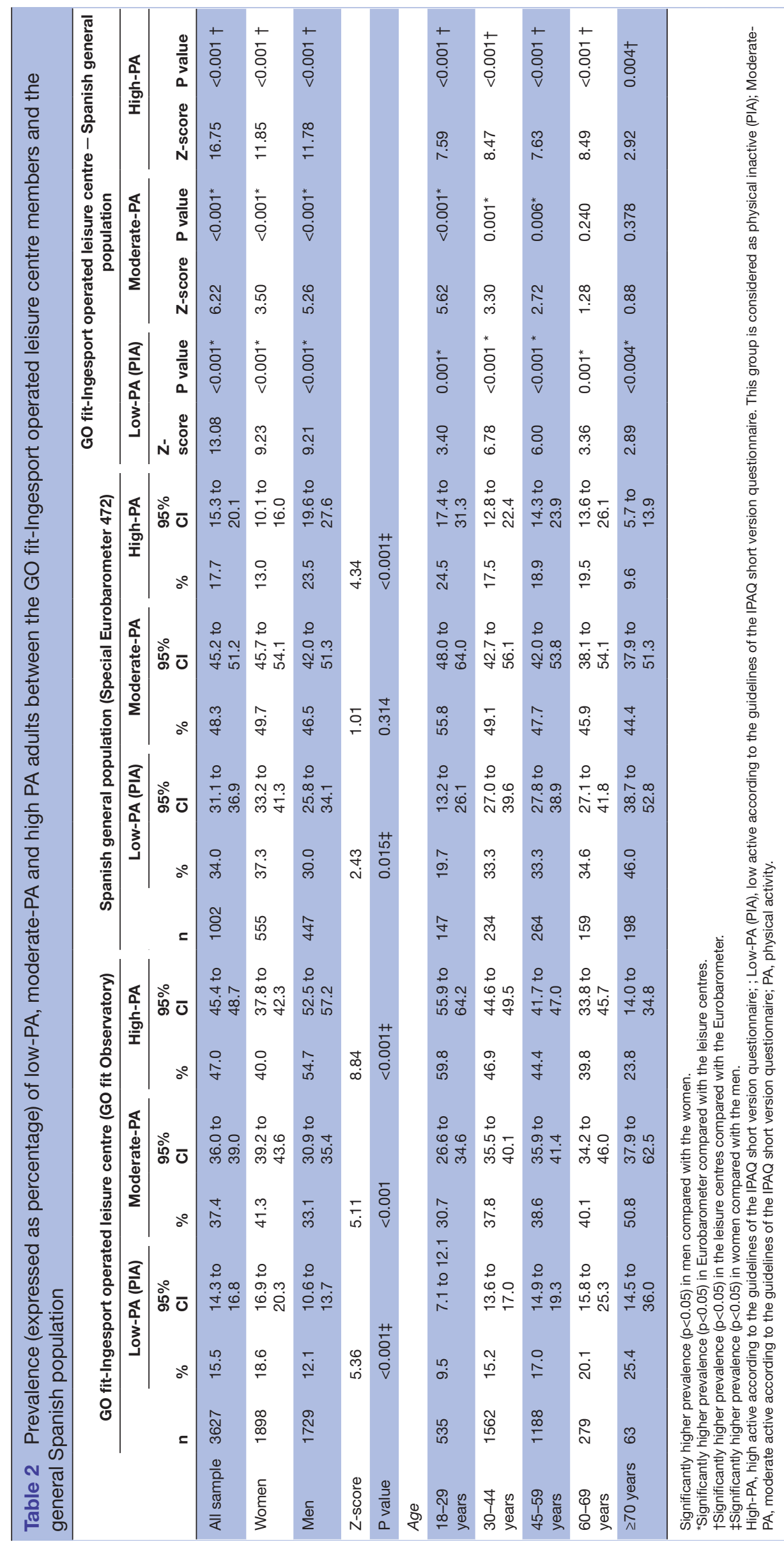

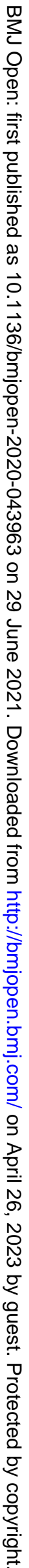




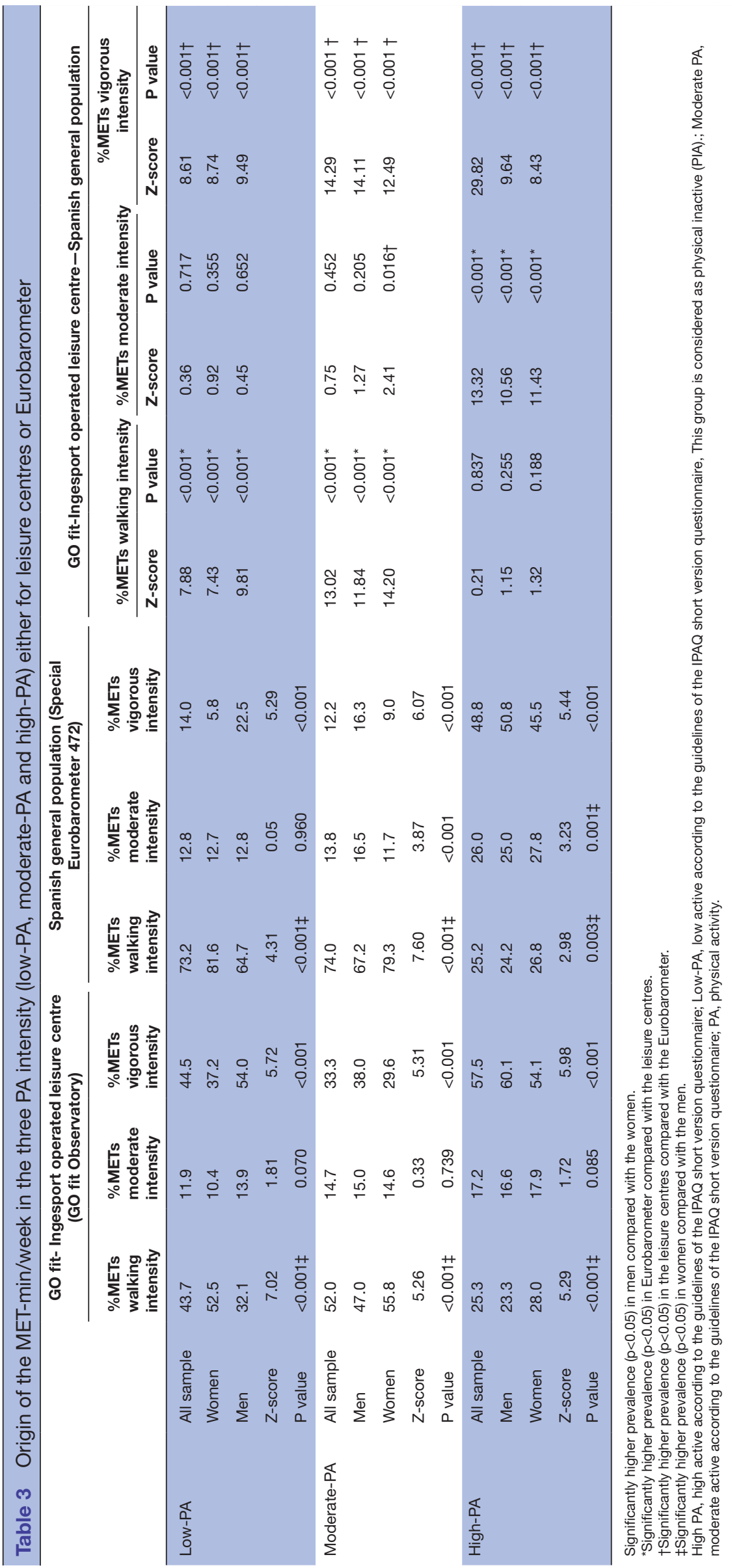

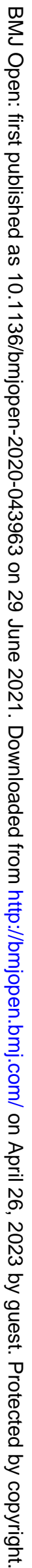




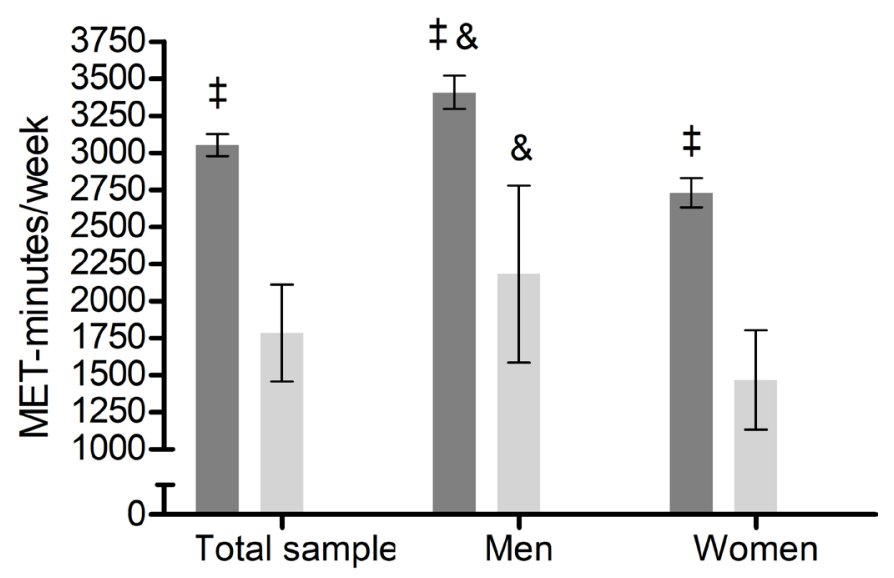

Ingesport-operated leisure centres Spanish general population

Figure 1 Average total MET-min/week between the leisure centre and the Eurobarometer for all participants and for men and women separately. ‡ Significantly higher MET-min/week $(p<0.05)$ in the leisure centres regarding the Eurobarometer. \& Significantly higher MET-min/week $(p<0.05)$ in men regarding the women. MET: metabolic equivalent.

both genders use these centres, their objectives to achieve by working out in fitness centres, and the existence of sociospatial gendering processes. ${ }^{38-40}$

This manuscript shows that the prevalence of PIA increases with the age both in leisure centres and in the general population, coinciding with previous studies that reported a higher prevalence of PIA in older adults. ${ }^{25} 26$ However, the lower prevalence of PIA in all age brackets for leisure centre members enhances the importance of these centres as places of exercise providers. ${ }^{202124}$ The prevalence of high-PA decreases with age in both samples, yet high-PA was more than two times as high in leisure centre members regardless of age. Therefore, although levels of regular PA are aged-related, members of leisure centres seem to perform more vigorous-PA than the general population ${ }^{24}$ may be due to the characteristics of the exercise that can be performed in these centres. ${ }^{2023} 41$ Among the different age groups studied, older adults $(\geq 60$ years old) are a significant target group for PA interventions due to the lower overall engagement in $\mathrm{PA},{ }^{25} 26$ and also because many older adults have chronic health conditions or disease as a consequence of PIA, or that can be improved by prescribed exercise. ${ }^{42} 43$ This study shows that up to $39.8 \%$ of adults between 60 and 69 years old and up to $23.8 \%$ of adults $>69$ years were classified in the high-PA group. Furthermore, contrary to the trend of the general population, the prevalence of moderate-PA in leisure centre members improves as age increases. Thus, as suggested by Watts $e t a l,{ }^{28}$ leisure centres seem to play an important role in supporting older people to stay active. Therefore, leisure centres can likely be considered effective environments for promoting and developing active living and healthy ageing interventions.
The origin of the PA level reported is also a new finding, although a previous study suggested that members from leisure centres exercise more intense than nonmembers. ${ }^{24}$ Gerovasili, et $a l,{ }^{31}$ explored the origin of total MET-min/week among the European Union Countries, however, they did not make subgroups according to their PA levels nor consider the gender and age of participants. The literature suggests that meeting PA guidelines reduces the likelihood of developing cardiovascular, metabolic and other non-communicable diseases, ${ }^{6} 44-46$ however, performing vigorous-PA seems to produce additional health benefits. ${ }^{37}$ 47-49 Therefore, even when meeting the PA guidelines there are increased benefits to including additional minutes of vigorous-PA. ${ }^{37} 47-49$ Vigorous-intensity PA represented a higher proportion of total MET-min/week in members of leisure centres regardless the PA group (low-PA (44.5\% vs $14.0 \%$ ), moderate-PA $(33.3 \%$ vs $12.2 \%)$ or high-PA $(57.5 \%$ vs $48.8 \%)$ ), while walking accounted for more than $70 \%$ of MET-min/week in the low-PA and moderate-PA groups of the general population. Thus, members of leisure centres, given the greater proportion of higher intensity PA, may derive additional health benefits compared with the general population. ${ }^{48}$

Previous studies have explored the average MET-min/ week in adults, ${ }^{31} 50$ however, this has not been done in leisure centre users. GO fit-Ingesport leisure centre members showed an average MET-min/week (3051.59) much higher than the general population of Spain, and comparable to the two most active European countries in 2013 (Latvia=3027; Estonia=2910).$^{31}$ On the other hand, the total MET-min/week average in 2013 for Spain ${ }^{31}$ are higher than those found in this study (2166 vs 1784.52), suggesting that the PA levels of Spanish households may have decreased in the last years. ${ }^{10}$ Regarding gender, the outcomes from total MET-min/week also corroborate that men reporting being more active than women. ${ }^{10} 2736$ However, once again, leisure centre members of both genders show significantly higher PA levels than the general population.

The ability of leisure centres to engage people from all ages, but specially women and older adults, enforces the suggestion that European countries should develop specific strategies to engage leisure centres in the overall mitigation of population-based PIA. ${ }^{17}$ These centres can also be used for targeting diseases related to PIA. ${ }^{28} 51$ We acknowledge that many leisure centre members do not regularly exercise within the centres, and that many members leave the centres within the first 6 months. ${ }^{52} 53$ Moreover, a significant proportion of new members report being inactive before enrolling ${ }^{53}$ while the cost of the membership fee might be a barrier for some people. ${ }^{54}$ Thus, we encourage policymakers and the fitness industry to work together in order to increase the accessibility to these centres to low-income people and to develop effective formulas to reduce the gender and age gaps that exist in PA habits. ${ }^{102526}$ Providing PA opportunities according to the gender and age preferences, 
eliminating sociospatial gendering barriers and applying behaviour change strategies in these centres might work to improve the effectiveness of leisure centres as PA providers and improve access to these places to disadvantaged groups. ${ }^{18} 38-4055$

Despite the large sample size used in this study, it is important to consider the following limitations. (a) It is possible that highly motivated members were more willing to respond to the survey compared with those who engaged in mostly low-PA, and that this could bias the results; (b) data from this work were based on selfreport questionnaires which may over-report PA levels, ${ }^{56}$ so caution should be despite large samples (c) the Eurobarometer truncate the solutions from the IPAQ questionnaire ${ }^{10}$ while the sample from the leisure centres used the classical open solutions, ${ }^{30}$ so the total minutes in each category of PA were artificially assumed according to the suggestion of Gerovasili et al. ${ }^{31}$ (d) It was not possible to manage the sample size of both databases used in this study. Thus, causality cannot be stressed from our data. A particular strength, however, is that all of the centres analysed were spread among 7 of the 17 Regions of Spain, thereby increasing external validity. Based on the main limitation of this study, future studies should combine device-based and self-report PA instruments to investigate differences in PA prevalence in these two populations. This would allow comparison of effects sizes between different instruments capable of assessing distinct PA constructs and identify any potential discrepancies according to age and gender.

\section{CONCLUSIONS}

Members of leisure centres are mostly active as only $15.5 \%$ of members of the members of the Spanish GO fit-Ingesport leisure centres reported to be low-PA, while $47.0 \%$ reported to be high-PA. Moreover, the members of leisure centres showed lower prevalence of PIA and a higher prevalence of high-PA than the Spanish population regardless gender and age. As a consequence, GO fit members showed higher MET-min/week than the general population. Differences in PA levels between men and women were confirmed either in leisure centres members or the general population. However, both men and women of GO fit-Ingesport leisure centres showed higher MET-min/week than the general population. Vigorous PA represented a higher proportion of total MET-min/week in leisure centres' members than in the general population regardless of the PA group (lowPA; moderate-PA; high-PA). Moreover, more than $70 \%$ of METs in the low-PA and moderate-PA of the Spanish population were due to walking.

\section{Author affiliations}

${ }^{1}$ Centre for Sport, Exercise and Life Sciences, Coventry University, Coventry, UK ${ }^{2} \mathrm{GO}$ fit LAB, Ingesport-G0 fit, Alcobendas, Spain

${ }^{3}$ Observatory of Healthy \& Active Living of Spain Active Foundation, Centre for Sport Studies, King Juan Carlos University, Madrid, Spain
${ }^{4}$ Faculty of Sports Sciences and Physical Education, Department of Physical Education and Sports, University of A Coruña, A Coruna, Galicia, Spain ${ }^{5}$ College of Health Sciences, University of Rhode Island, Kingston, Rhode Island, USA ${ }^{6}$ Advanced Wellbeing Research Centre, College of Health, Sheffield Hallam University College of Health Wellbeing and Life Sciences, Sheffield, UK

Contributors JLF, XM and AJ conceptualised the research; JLF, AL-V, XM and AJ set the methodology followed in this research; JLF and AL-V completed the data curation and formal analysis; JLF, AL-V, XM and AJ reviewed and validated the data analysis; JLF and AL-V drafted the manuscript; JLF, AL-V, XM, EH, IC, GL and AJ critical reviewed the manuscript and completed the required changes; $E H, I C$, $\mathrm{GL}$ and AJ coordinated the different stages of the research. All authors have read and agreed to the published version of the manuscript and agree the order of presentation of the authors.

Funding The authors have not declared a specific grant for this research from any funding agency in the public, commercial or not-for-profit sectors.

Competing interests JLF acknowledges that his $\mathrm{PhD}$ studies have been funded by G0 fit-Ingesport. AL-V also acknowledges he is a postdoctoral research fellow funded by G0 fit-Ingesport at the Centre for Sports Studies of King Juan Carlos University. AJ acknowledges he serves at a fractional role as Chief Research \& Innovation Officer at GO fit-Ingesport.

Patient and public involvement Patients and/or the public were not involved in the design, or conduct, or reporting, or dissemination plans of this research.

Patient consent for publication Not required.

Ethics approval Ethical approval for this study was not required. Eurobarometer 472 database has been published by the European Commission and, it is public access. Go fit database was provided by a Spanish leisure centres operator (G0 fit-Ingesport Health \& Spa Consulting SA) that periodically survey its customers about their current PA levels and service satisfaction. Customers were informed that the conducted survey could be used to conduct market studies and also research studies. No personal data or data that could be used to identify a person was included in G0 fit database.

Provenance and peer review Not commissioned; externally peer reviewed.

Data availability statement Data are available in a public, open access repository. Data are available upon reasonable request. The raw data of the Eurobarometer 472 is owned by the European Commission and available online: https://dbk. gesis.org/dbksearch/sdesc2.asp?no=6939\&search=Physicalfitnessandexercise\& search2=\&field $=$ all \&field $2=\& D B=e \& t a b=0 \&$ notabs $=\& n f=1 \& a f=\& \|=10$. The raw data from the Spanish fitness centre operator is owned by GO fit-Ingesport Health \& Spa Consulting SA. To request access to this data contact to the corresponding author.

Open access This is an open access article distributed in accordance with the Creative Commons Attribution Non Commercial (CC BY-NC 4.0) license, which permits others to distribute, remix, adapt, build upon this work non-commercially, and license their derivative works on different terms, provided the original work is properly cited, appropriate credit is given, any changes made indicated, and the use is non-commercial. See: http://creativecommons.org/licenses/by-nc/4.0/.

ORCID iD

Jorge López Fernández http://orcid.org/0000-0001-9489-3249

\section{REFERENCES}

1 World Health Organization. Global recommendations on physical activity for health. Geneva, Switzerland: World Health Organization, 2010.

2 Tremblay MS, Aubert S, Barnes JD, et al. Sedentary behavior research network (SBRN) - terminology consensus project process and outcome. Int J Behav Nutr Phys Act 2017;14:75.

3 Bull FC, Al-Ansari SS, Biddle S, et al. World Health organization 2020 guidelines on physical activity and sedentary behaviour. $\mathrm{Br} J$ Sports Med 2020;54:1451-62.

4 Lee I-M, Shiroma EJ, Lobelo F, et al. Effect of physical inactivity on major non-communicable diseases worldwide: an analysis of burden of disease and life expectancy. Lancet 2012;380:219-29.

5 Stamatakis E, Bull FC. Putting physical activity in the 'must-do' list of the global agenda. Br J Sports Med 2020;54:1445-6.

6 Ding D, Lawson KD, Kolbe-Alexander TL, et al. The economic burden of physical inactivity: a global analysis of major non-communicable diseases. Lancet 2016;388:1311-24. 
7 EU Working Group "Sport and Health. Eu physical activity guidelines recommended policy actions in support of healthenhancing physical activity. Brussels, Belgium: European Commission, 2008.

8 World Health Organization. Global action plan on physical activity 2018-2030: more active people for a healthier world. Geneva, Switzerland: World Health Organization, 2018.

9 World Health Organization. Global action plan for the prevention and control of noncommunicable diseases 2013-2020. Geneva, Switzerland: World Health Organization, 2013.

10 Mayo X, Liguori G, Iglesias-Soler E, et al. The active living gender's gap challenge: 2013-2017 Eurobarometers physical inactivity data show constant higher prevalence in women with no progress towards global reduction goals. BMC Public Health 2019;19:1677.

11 Mayo X, Del Villar F, Iglesias-Soler E, et al. A retrospective analysis of policy development on compliance with World Health organization's physical activity recommendations between 2002 and 2005 in European Union adults: closing the gap between research and policy. BMC Public Health 2018;18:1081.

12 Glass TA, McAtee MJ. Behavioral science at the crossroads in public health: extending horizons, envisioning the future. Soc Sci Med 2006:62:1650-71.

13 Byambasukh O, Snieder H, Corpeleijn E. Relation between leisure time, commuting, and occupational physical activity with blood pressure in 125402 adults: the lifelines cohort. J Am Heart Assoc 2020;9:1-23.

14 Rosique-Esteban N, Babio N, Díaz-López A, et al. Leisure-Time physical activity at moderate and high intensity is associated with parameters of body composition, muscle strength and sarcopenia in aged adults with obesity and metabolic syndrome from the PREDIMED-Plus study. Clin Nutr 2019;38:1324-31.

15 Liu Y, Shu X-O, Wen W, et al. Association of leisure-time physical activity with total and cause-specific mortality: a pooled analysis of nearly a half million adults in the Asia cohort Consortium. Int $J$ Epidemiol 2018:47:771-9.

16 Deloitte, EuropeActive. European health \& fitness market report (EHFMR). Deloitte, 2019.

17 Beedie C, Mann S, Jimenez A. Community fitness center-based physical activity interventions: a brief review. Curr Sports Med Rep 2014:13:267-74.

18 Lopez-Fernandez J, Jiménez A. It is time for the fitness \& wellness industry to lead the agenda against physical inactivity. Res Invest Sports Med 2018;2:1-3.

19 Annesi J. Effects of a cognitive behavioral treatment package on exercise attendance and drop out in fitness centers. Eur J Sport Sci 2003;3:1-16.

20 IHRSA. The IHRSA global report. Boston: International Health Racquet and Sportsclub Association, 2018.

21 Clavel I, Iglesias-Soler E, Garcia-Unanue J. A model for predicting dropouts from physical activity interventions in leisure centres. Sport Sci Health 2020:1-8.

22 Paruthi G, Raj S, Colabianchi N. Finding the sweet spot (S) understanding context to support physical activity plans. Proc ACM Inter Mobile Wearable Ubiquit Tech 2018;2:1-17.

23 Kaphingst KA, Bennett GG, Sorensen G, et al. Body mass index, physical activity, and dietary behaviors among members of an urban community fitness center: a questionnaire survey. BMC Public Health 2007;7:181

24 Schroeder EC, Welk GJ, Franke WD, et al. Associations of health club membership with physical activity and cardiovascular health. PLoS One 2017:12:e0170471.

25 Bauman A, Bull F, Chey T, et al. The International prevalence study on physical activity: results from 20 countries. Int J Behav Nutr Phys Act 2009;6:21.

26 Carlson SA, Fulton JE, Schoenborn CA, et al. Trend and prevalence estimates based on the 2008 physical activity guidelines for Americans. Am J Prev Med 2010;39:305-13.

27 Guthold R, Stevens GA, Riley LM, et al. Worldwide trends in insufficient physical activity from 2001 to 2016: a pooled analysis of 358 population-based surveys with 1.9 million participants. Lancet Glob Health 2018;6:e1077-86.

28 Watts P, Webb E, Netuveli G. The role of sports clubs in helping older people to stay active and prevent frailty: a longitudinal mediation analysis. Int J Behav Nutr Phys Act 2017:14:95.

29 European Opinion Research Group. Special Eurobarometer 472. Brusels, Belgium: European Commision, 2018.

30 IPAQ Group. International physical activity questionnaire. guidelines for data processing and analysis of the International physical activity questionnaire (IPAQ) - short and long forms, 2005.
31 Gerovasili V, Agaku IT, Vardavas $\mathrm{Cl}$, et al. Levels of physical activity among adults 18-64 years old in 28 European countries. Prev Med 2015;81:87-91.

32 Cheng HL. A simple, easy-to-use spreadsheet for automatic scoring of the International physical activity questionnaire (IPAQ) short form. ResearchGate 2016.

33 Gjestvang C, Stensrud T, Hansen BH, et al. Are fitness Club members likely to meet the current physical activity recommendations? Trans/ Sports Med 2020;3:75-83.

34 Hansen BH, Kolle E, Steene-Johannessen J, et al. Monitoring population levels of physical activity and sedentary time in Norway across the lifespan. Scand J Med Sci Sports 2019;29:105-12.

35 Loyen A, Clarke-Cornwell AM, Anderssen SA, et al. Sedentary time and physical activity surveillance through accelerometer pooling in four European countries. Sports Med 2017;47:1421-35.

36 Mielke GI, da Silva ICM, Kolbe-Alexander TL, et al. Shifting the physical inactivity curve worldwide by closing the gender gap. Sports Med 2018:48:481-9.

37 Swain D, Franklin B, Williams P. Cardioprotective benefits of vigorous physical activity: the risk benefit issue. In: The medical roundtable cardiovascular edition. , 2020: 1, 167-75.

38 Coen SE, Rosenberg MW, Davidson J. "It's gym, like g-y-m not J$\mathrm{i}-\mathrm{m} "$ : Exploring the role of place in the gendering of physical activity. Soc Sci Med 2018;196:29-36.

39 Salvatore J, Marecek J. Gender in the gym: Evaluation concerns as barriers to women's weight lifting. Sex Roles 2010;63:556-67.

40 Maclntosh E, Law B. Should I stay or should I go? exploring the decision to join, maintain, or cancel a fitness membership. Manag Sport Leis 2015;20:191-210.

41 Wickham JB, Mullen NJ, Whyte DG, et al. Comparison of energy expenditure and heart rate responses between three commercia group fitness classes. J Sci Med Sport 2017;20:667-71.

42 Hoffmann TC, Maher CG, Briffa T, et al. Prescribing exercise interventions for patients with chronic conditions. CMAJ 2016;188:510-8

43 Picorelli AMA, Pereira LSM, Pereira DS, et al. Adherence to exercise programs for older people is influenced by program characteristics and personal factors: a systematic review. $J$ Physiother 2014;60:151-6.

44 Fiuza-Luces C, Santos-Lozano A, Joyner M, et al. Exercise benefits in cardiovascular disease: beyond attenuation of traditional risk factors. Nat Rev Cardiol 2018;15:731-43.

45 Mozumdar A, Liguori G. Persistent increase of prevalence of metabolic syndrome among U.S. adults: NHANES III to NHANES 1999-2006. Diabetes Care 2011;34:216-9.

46 Anderson E, Durstine JL. Physical activity, exercise, and chronic diseases: a brief review. Sports Med Health Sci 2019;1:3-10.

47 Soares-Miranda L, Sandercock G, Vale S, et al. Benefits of achieving vigorous as well as moderate physical activity recommendations: evidence from heart rate complexity and cardiac vagal modulation. $J$ Sports Sci 2011;29:1011-8.

48 Stamatakis E, Lee I-M, Bennie J, et al. Does strength-promoting exercise confer unique health benefits? A pooled analysis of data on 11 population cohorts with all-cause, cancer, and cardiovascular mortality endpoints. Am J Epidemiol 2018;187:1102-12.

49 Swain DP, Franklin BA. Comparison of cardioprotective benefits of vigorous versus moderate intensity aerobic exercise. Am J Cardiol 2006:97:141-7.

50 Cocca A, Liukkonen J, Mayorga-Vega D, et al. Health-related physical activity levels in Spanish youth and young adults. Percept Mot Skills 2014;118:247-60.

51 Beedie C, Mann S, Domone S. Effects on cardiovascular risk factors of three 48-week community-based exercise interventions. Med Sci Sports Exerc 2016;48.

52 Sperandei S, Carvalho Vieira M, Reis AC. Adherence to physical activity in an unsupervised setting: the case of lapse and return to practice in a Brazilian fitness center. AJSPO 2019;6:95-108.

53 Sperandei S, Vieira MC, Reis AC. Adherence to physical activity in an unsupervised setting: explanatory variables for high attrition rates among fitness center members. J Sci Med Sport 2016;19:916-20.

54 Moreno-Llamas A, García-Mayor J, De la Cruz-Sánchez E. Physical activity barriers according to social stratification in Europe. Int $J$ Public Health 2020;65:1477-84.

55 Middelkamp J, van Rooijen M, Wolfhagen P, et al. The effects of a self-efficacy intervention on exercise behavior of fitness Club members in 52 weeks and long-term relationships of Transtheoretical model constructs. J Sports Sci Med 2017;16:163-71.

56 Steene-Johannessen J, Anderssen SA, van der Ploeg HP, et al. Are self-report measures able to define individuals as physically active or inactive? Med Sci Sports Exerc 2016;48:235-44. 